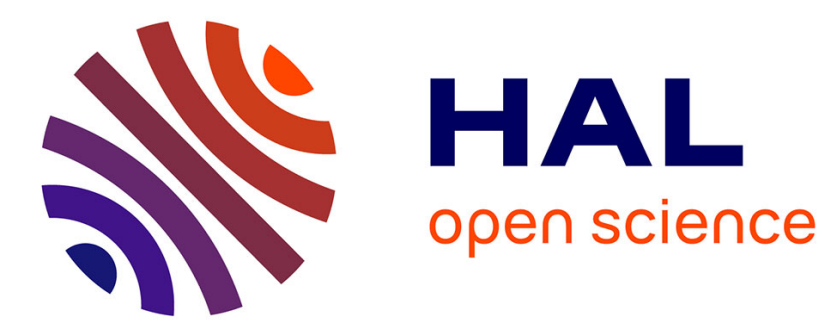

\title{
Spring Phenology of the Boreal Ecosystems
}

Nicolas Delbart

\section{To cite this version:}

Nicolas Delbart. Spring Phenology of the Boreal Ecosystems. Arctic Hydrology, Permafrost and Ecosystems, Springer International Publishing; Springer International Publishing, pp.559-581, 2021, 10.1007/978-3-030-50930-9_19 . hal-03232273

\section{HAL Id: hal-03232273 \\ https://hal.science/hal-03232273}

Submitted on 21 May 2021

HAL is a multi-disciplinary open access archive for the deposit and dissemination of scientific research documents, whether they are published or not. The documents may come from teaching and research institutions in France or abroad, or from public or private research centers.
L'archive ouverte pluridisciplinaire HAL, est destinée au dépôt et à la diffusion de documents scientifiques de niveau recherche, publiés ou non, émanant des établissements d'enseignement et de recherche français ou étrangers, des laboratoires publics ou privés. 


\title{
Spring phenology of the boreal ecosystems
}

\author{
Nicolas Delbart \\ Université de Paris, UMR CNRS 8236 Laboratoire des Energies de Demain / UMR8586 PRODIG, F- \\ 75013 Paris, France
}

\begin{abstract}
Ecosystem phenology, i.e. the timing of key biological events, is often considered as both a witness and an actor of climate change. Phenological interannual variations and decadal changes reflect climate variability and trends. Deciduous plant phenology also directly influences the carbon, water and energy exchanges of the ecosystem with the atmosphere. In the northern forests, a trend to earlier spring has been widely reported, often based on remote sensing methods. This trend is suggested to explain a part of the residual carbon sink. However methodological issues, especially related to the combined effects of the vegetation and of the snow cover seasonal changes on the remote sensing signal, were found to affect the results.

This chapter describes a remote sensing green-up retrieval method designed to avoid signal contamination by snow. The result validation with ground observations showed that the method catches the interannual variations in phenology of the plant community. Changes in the 1998-2017 are analyzed and positioned in a longer term. This shows that the most persistent feature over the last decades is a large-scale shift in the green-up date at the end of the 1980's, and that the green-up date has not recovered yet to its status prior to 1987 . Finally the green-up date maps were used to represent phenology in the northern ecosystem carbon budget simulations. No unidirectional effect of phenological changes in the annual carbon balance could be identified because of a complex interplay between vegetation, water resources and climate.
\end{abstract}

\section{Introduction}

Phenological shifts, i.e. changes in the timing of key biological events within the year, are often reported among the most obvious impacts of climate changes and climate variability on ecosystems (Walther et al., 2002; Parmesan \& Yohe, 2003; Root et al., 2003; Walther, 2010; Bellard et al., 2012). Especially spring phenology has advanced during the last decades with a number of days that varies according to the organisms. Phenological changes also display feedbacks to the atmosphere through several processes, including changes in the seasonal courses and the annual balances of energy, water and carbon exchanges (Richardson, 2013). Therefore research on phenology addresses questions regarding the observation strategies from the plant scale to the biome scale, changes in phenology in relationship with climate changes, or the consequences of these changes. Answering these questions is crucial in the boreal ecosystems where the observed warming is especially strong (Solomon, 2007) with multiple consequences on physical and biological functions (Hinzman et al., 2005; Post et al., 2009) and where the warming is predicted to be enhanced in the future (IPCC, 2013). 
This chapter summarizes the research in the boreal ecosystem phenology using remote sensing based methods. It describes the methodologies that were developed to map the date of green-up at the scale of the circumpolar forests and low-arctic tundra with reduced influence of snowmelt on the radiometric signal. It also documents the variations in phenology in boreal North America and Eurasia boreal forests over the last decades. Finally, it reports how the remote sensing green-up maps were used to improve the modelling of the carbon budget of northern ecosystems.

\section{Mapping the date of the beginning of the boreal spring with remote sensing}

The diversity of impacts of phenological changes has resulted in a diversity of methods of observation and analyses, such as the networks of field observations by scientists (Menzel, 2000) or by citizens (Beaubien \& Hamann, 2011b), the modelling (Schwartz et al., 2006) or remote sensing. Observing phenology using repetitive optical remote sensing has been experimented since the 1970's (Dethier et al., 1973; Rea \& Ashley, 1976; Vinogradov, 1977). These studies, based on Landsat-1 data, introduced key-concepts on which recent works about land surface phenology still rely, such as the radiometric data pre-processing, use of spectral indices combining radiometric measurements in the visible and near-infrared spectral domains, or the validation via ground observations. These concepts were further applied to large swath optical remote sensing which allows high frequency of radiometric measurement at the global scale (Justice et al., 1985, 1986; Townshend \& Justice, 1986), revealing an increase in the greenness of ecosystems at $45-75^{\circ} \mathrm{N}$ latitudes, especially in the spring interpreted as an advance of the beginning of the growing season during 1982-1991 (Myneni et al., 1997, 1998). This advance matched a similar trend in ground phenology observations (Schwartz, 1998) and explained the changes in the seasonal variations of atmospheric carbon dioxide concentrations as increased greenness is associated with increase in carbon uptake (Keeling et al., 1996). Remote sensing has also been used to study phenology of specific ecosystems, in mountainous areas (Colombo, 2011; Guyon, 2011), temperate forests (Duchemin et al., 1999; Soudani, 2008), semi-arid areas like Sahel (Guan, 2014; Meroni et al., 2014), boreal regions (Suzuki et al., 2003; Zeng, 2013), or even tropical forests (Pennec et al., 2011). Nevertheless the exact meaning of the land surface phenology (LSP) metrics, i.e. the recorded timing of the radiometric transition, is still questioned for various reasons (Helman, 2018). The LSP metrics differ strongly with both the data pre-processing and extraction methods (Schwartz et al., 2002; Morisette et al., 2009; White et al., 2009; Helman, 2018) so that validation, for example, using ground phenology observations and photosynthesis measurements remains a key issue (Badeck et al., 2004; Liang et al., 2011; Pouliot, 2011; Gonsamo, 2013; Misra et al., 2016). 


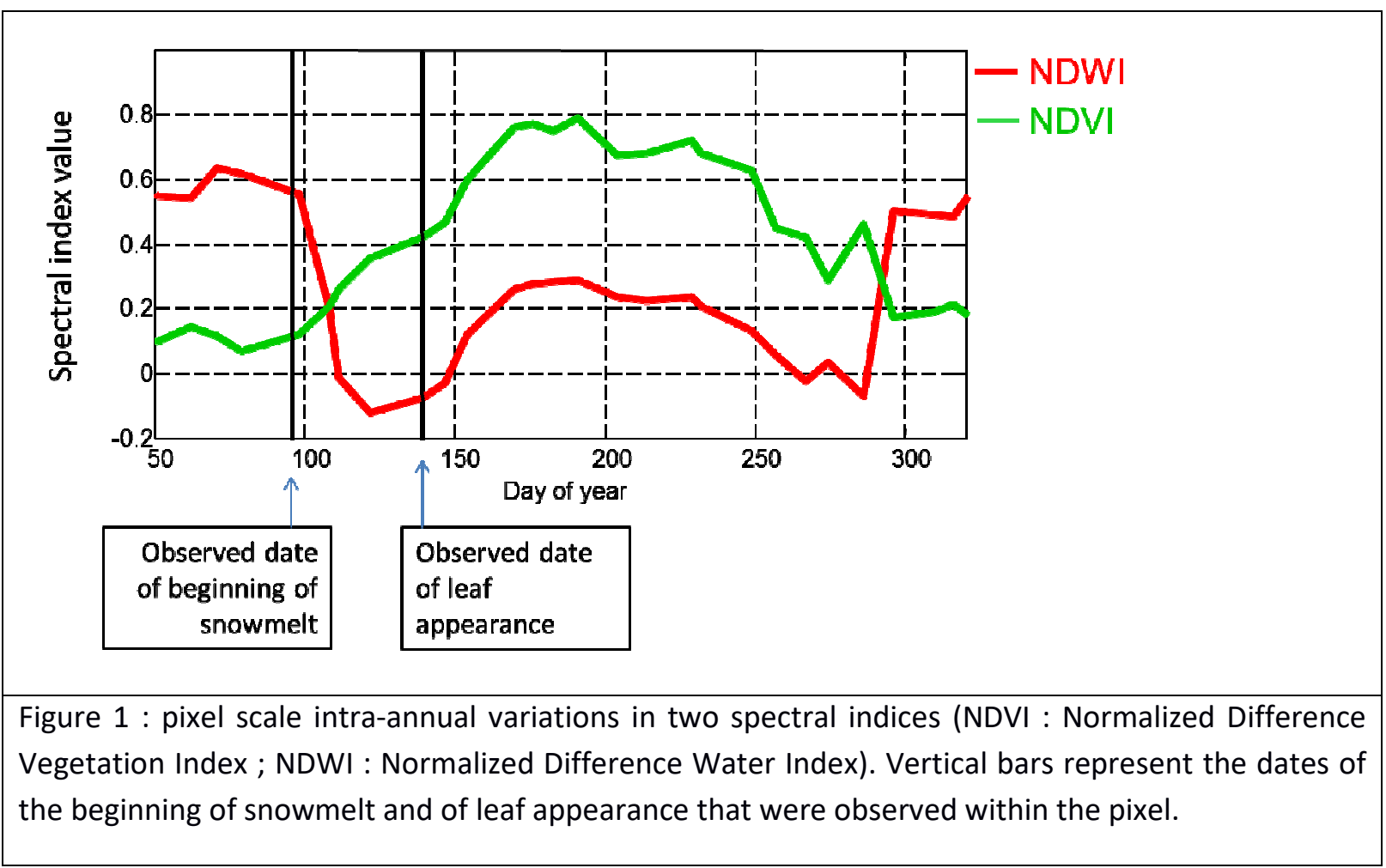

One source of uncertainty is specific to the boreal regions and to the mountainous areas when observing the start of the growing season : snowmelt at spring strongly influences the radiometric changes (Moulin et al., 1997; Shabanov et al., 2002; Dye \& Tucker, 2003). The widely used Normalized Difference Vegetation Index (NDVI), defined as the normalized difference of reflectance in the red and the near infrared spectral bands, increases when the snow cover fraction in the pixel decreases (Fig. 1), even without any change in the vegetation, because its denominator decreases (Suzuki et al., 2011). The initial increase in NDVI must therefore not be interpreted as related to foliage expansion. Thus some proposed methods have been consisted in catching the time at which NDVI exceeds a relatively high threshold (Suzuki et al., 2003). In other methods snow affected value are replaced by snow-free values (Beck et al., 2006; Park et al., 2016). Other indices based on the same spectral bands were also developed using radiative transfer simulations to reduce the impact of snow cover variations (Jin et al., 2017). Alternatively, a method based on the Normalized Difference Water Index (NDWI), which is the normalized difference of near infrared (NIR) and shortwave infrared reflectance (SWIR) was proposed (Delbart et al., 2005). NDWI decreases with the progressive disappearance of the snow cover, and increases during the foliage development (Fig. 1). The green-up date is recorded as the time when the NDWI starts increasing. Precisely it is taken as the last date within the March-July period when NDWI has increased by less than $20 \%$ of its total increase in this period. This method was applied to SPOT VEGETATION S10 data. SPOT-VEGETATION is a push-broom sensor, which ensures that the spatial resolution is much more constant with the incidence angle than with the commonly used whisk-broom sensors MODIS and AVHRR (Helman, 2018). The S10 data give a reflectance value for four spectral bands once every ten days, selected among all the measurements acquired at least once daily. The selected value is the "best" 
measurement that has been made during the 10 day period, following the "maximum value composite" method (Holben, 1986). This preprocessing aims at minimizing the signal contamination by aerosols and clouds. The exact date of the selected measurement is given individually for each pixel.

The green-up maps were compared to ground measurements of deciduous tree leaf appearance date for ten taiga sites in Siberia, showing a root mean square error (RMSE) of 8.7 days, with no bias (Delbart et al., 2005). The method was further tested at a few more sites in other parts of boreal Eurasia (2008) and at one site in Alaskan tundra (Delbart \& Picard, 2007), showing similar agreements. The green-up date averaged at the regional scale reproduces a large part of the interannual variations in the leafing date observations at several locations within the region (Delbart et al., 2008). It was also compared to phenological observations by citizens in Canada (Delbart et al., 2015) : lower agreement was then found at the site scale, likely because of the landscape heterogenity around the observation sites and within the pixel. This lower agreement consisted in a higher non-systematic error only, as the green-up date remained unbiased with ground observations. Moreover, this comparison allowed to determine that the green-up date is related to deciduous tree leaf appearance even in urban lansdscapes and evergreen dominated forests. This is true only if the NDWI increase is large enough to be significant, which occurs only if the deciduous vegetation is largely present in the pixel (Delbart et al., 2005). The agreement between the green-up date and the deciduous tree leaf appearance indirectly confirms that our metrics is not related to the needle appearance in the evergreen forests. The retrieval is inefficient for pixels dominated by water or agriculture (Delbart et al., 2015), which must be excluded from the produced dataset (see next section). However, when averaged over larger regions the remote sensing green-up date time series was shown to reproduce interannual variability in phenology not only in the timing of leafing-out but also in the flowering time (Delbart et al., 2015), because various spring phenophase interannual variations are generally related to spring air temperature variations (Fig. 2). Furthermore, the evaluation of the method in mountainous areas show that it was more efficient than the NDVI based methods at lower elevations but less efficient at higher altitudes (Dunn \& de Beurs, 2011). The NDWI was also combined with the NDVI to evaluate phenology in the eucalyptus forests of the Australian Alps (Thompson, 2015; Thompson \& Paull, 2017).

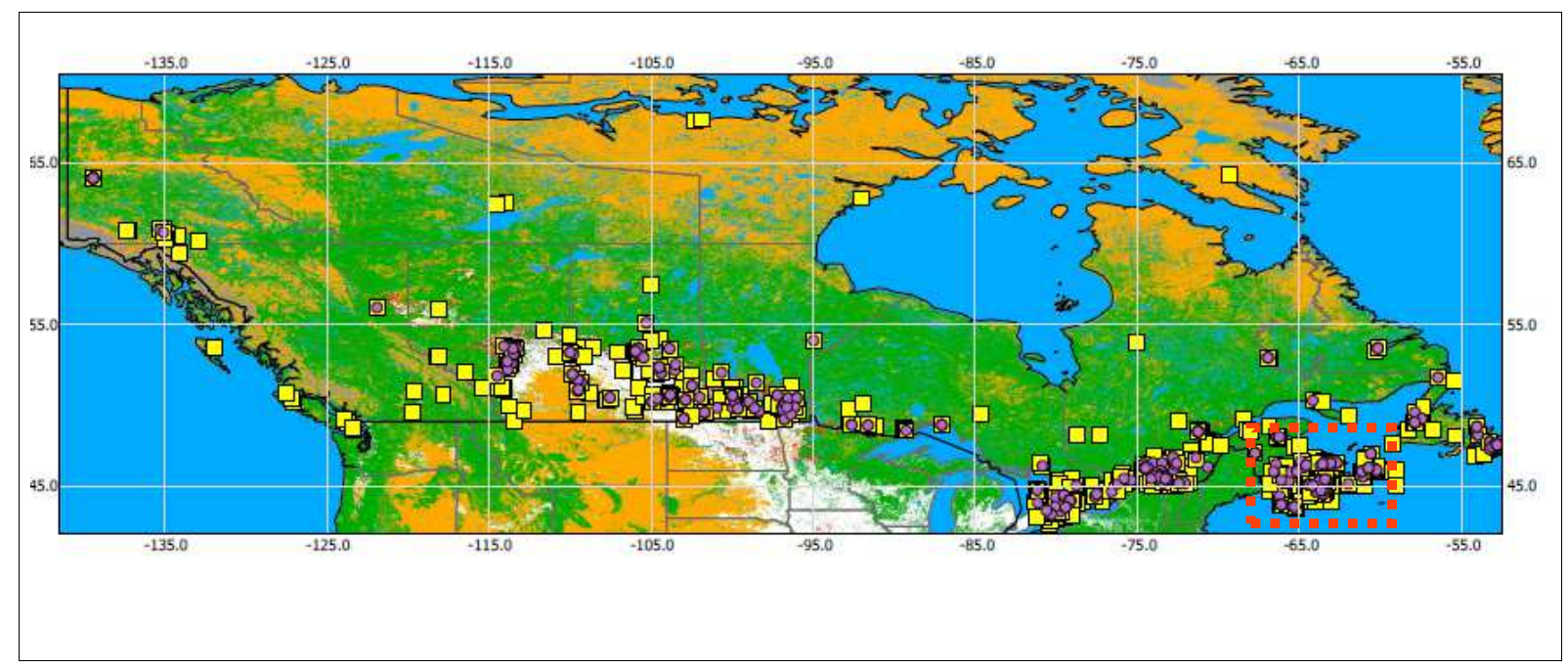




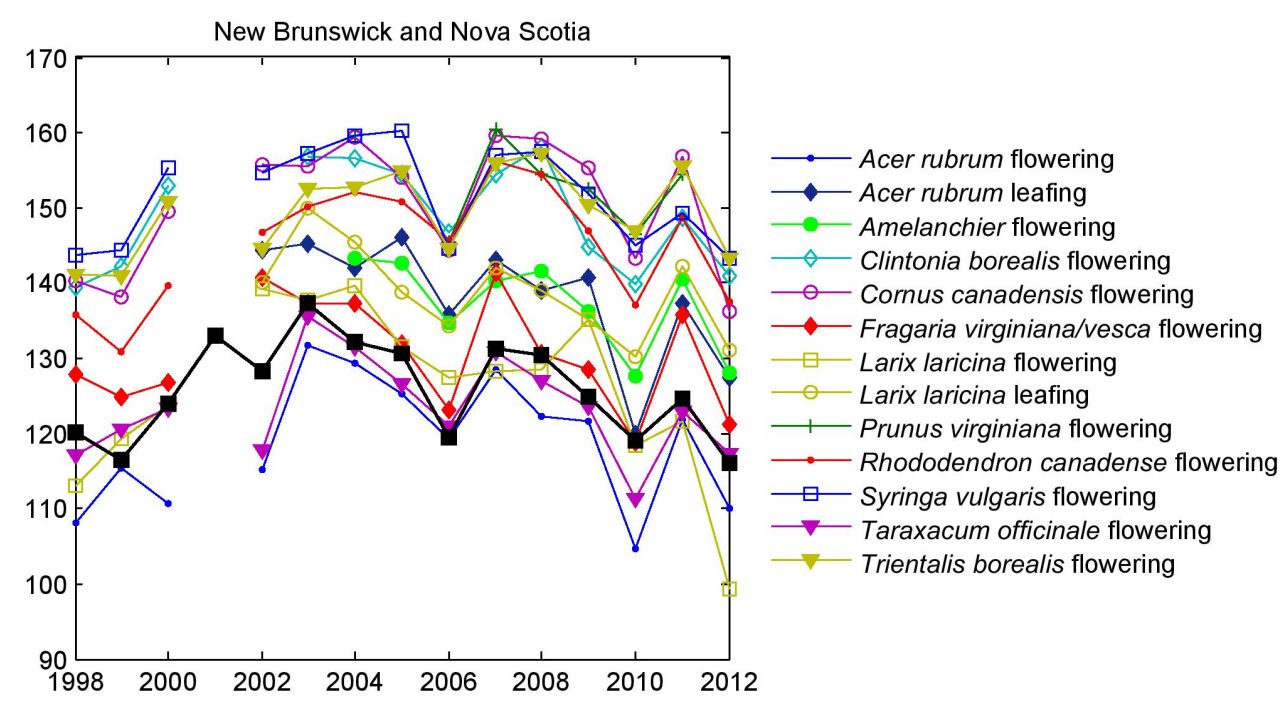

Fig. 2 : Time series of phenological events (first flowering and leaf out) resulting from the aggregation at the scale of New Brunswick-Nova Scotia region (delimited in the top panel) of the individual site observations by citizen scientists, and time series of the remote sensing green-up dates using the NDWI-VGT method (Delbart et al., 2005) (black squares). Site observations were collected in the framework of the PlantWatch project (Beaubien \& Hamann, 2011a). The spatial aggregation of the in-situ observations is derived from Hakkinen et al., (1995). Source : (Delbart et al., 2015).

The method could be applied to SPOT-VEGETATION dataset starting in 1998. In order to extend the study period back to 1982, the results were used to improve the AVHRR NDVI based threshold method (Suzuki et al., 2003) by adjusting the threshold value for each pixel individually (Delbart et al., 2006). This was possible using the overlap between the SPOT-VEGETATION dataset and the AVHRR Pathfinder 10-day composite dataset (James \& Kalluri, 1994) : for each common year between the two datasets, the AVHRR NDVI value at the green-up date given by our algorithm applied to SPOT-VEGETATION data was recorded. For this purpose, both AVHRR Pathfinder NDVI and SPOT-VEGETATION reflectance was first re-sampled to a common $0.1^{\circ}$ spatial resolution. The threshold map was obtained as the multi-year average value of these NDVI. Then, for all years from 1982, the green-up date was recorded as the date when the seasonal course of AVHRR NDVI reached the pixel-specific threshold (PST). The method was named as PST-NOAA. The produced results showed negligible bias and an RMSE equal to 8 days when validated in Siberia. Associated with the SPOT-VEGETATION based method applied at the $0.1^{\circ}$ spatial resolution, it could track the interannual variations of the observed tree leaf appearance date in boreal forests (Fig.3) and tundra shrublands that have occurred since 1982 (Delbart \& Picard, 2007; Delbart et al., 2008) (see below). 


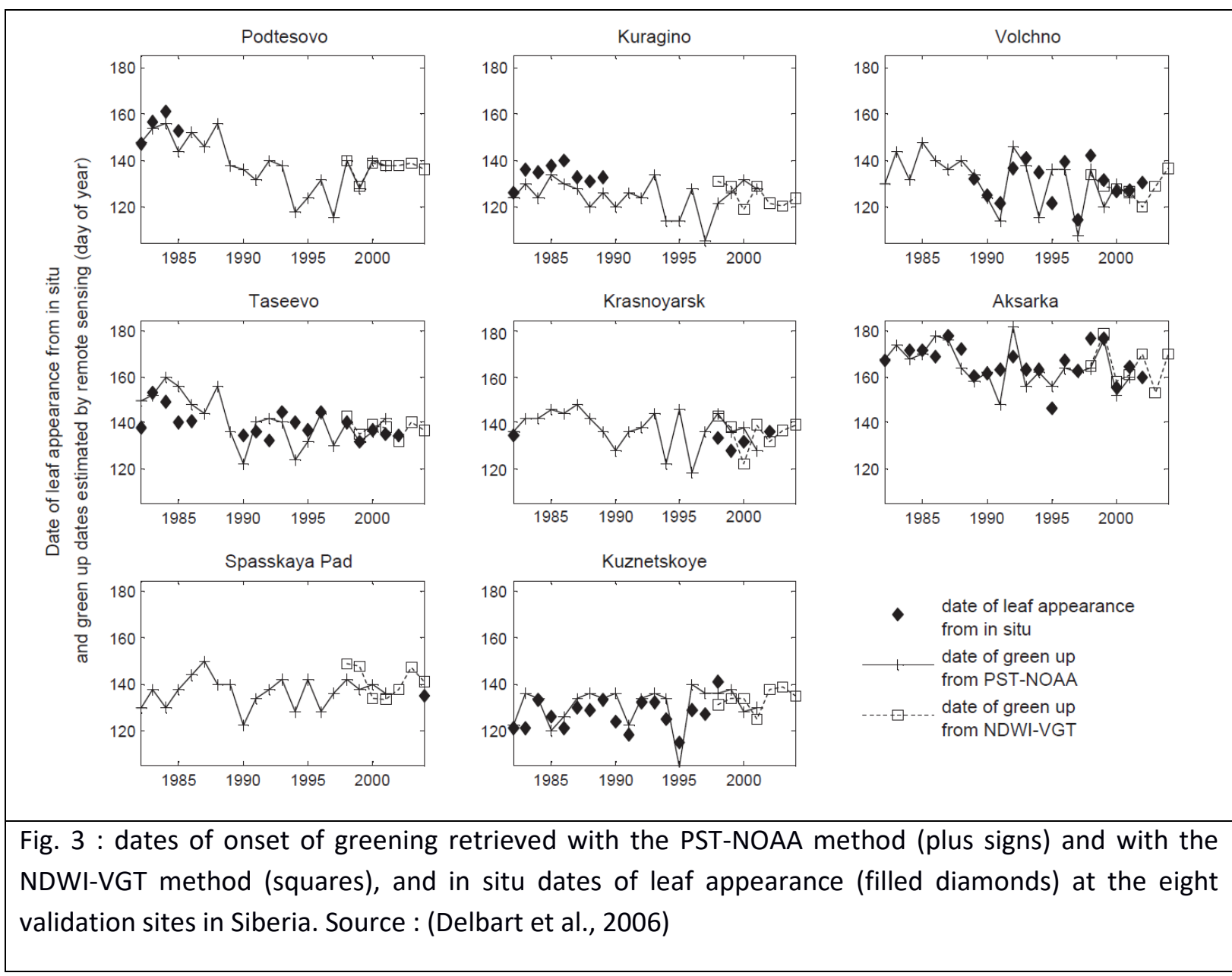

\section{Phenology : witness of climate change and variability in the boreal regions}

\subsection{Phenology trend and interannual changes during 1982-2005}

The dataset of green-up date maps resulting from our two remote sensing methods (Delbart et al., 2005,2006 ) was used to analyze the interannual variations in phenology in boreal Eurasia (Delbart et al., 2008) and in circumpolar tundra (Delbart \& Picard, 2007) during 1982-2005. These times series were complemented by those from a phenology model based on air temperature only (Picard et al., 2005), to relate the observed changes to climate and to elongate the study period. Model calibration procedure is described in the next section. These studies also benefited from a few long term time series of ground observations of leaf appearance date.

On average, over the whole Eurasian taiga area, a five-day shift in phenology between 1987 and 1990 was found (Delbart et al., 2008), directly explained by climate as it was reproduced by the modelling based on air temperature (Fig. 4). This change was confirmed by other methods and was shown to be directly related to the shift in the North Atlantic Oscillation (NAO), thus a witness to changes of the global climate, and interpreted as the main mechanism behind the Siberian carbon sink (Buermann, 2016). This biome scale average hides contrasted regional variations (Fig. 5). During the study period (1982-2005) some regions like Yakoutia in eastern Siberia showed almost no trend, and others 
displayed an advance (Fig. 5). The largest trend was found for Central Siberia with a 20-day advance. However, long term ground observations and the model applied to temperatures at meteorological stations within the sub-region have revealed that half of this large advance was explained by exceptionally late spring in 1983 and 1984. This is associated with cold temperatures in this region at the beginning of the period that is accessible through remote sensing, and thus must be attributed to climate variability and not to climate change. The model also revealed some fluctuations in phenology in the longer term, such as a trend to later spring in 1936-1960 for the whole Siberia from the east of the Ob River. On the contrary, several successive periods of advances have occurred since 1936 in the western part of the study area, with no period showing a trend to later spring. It was also found that the interannual variations in spring phenology in central Siberia were correlated with the south oscillation index, with late springs during El Niño years and early springs during La Niña years, linking with the dominant wind directions, very different between the two types of years (VicenteSerrano et al., 2006). In the sub-Arctic tundra, advances in spring over the last decades were found in north Alaska and in north-west Siberia (Delbart \& Picard, 2007).

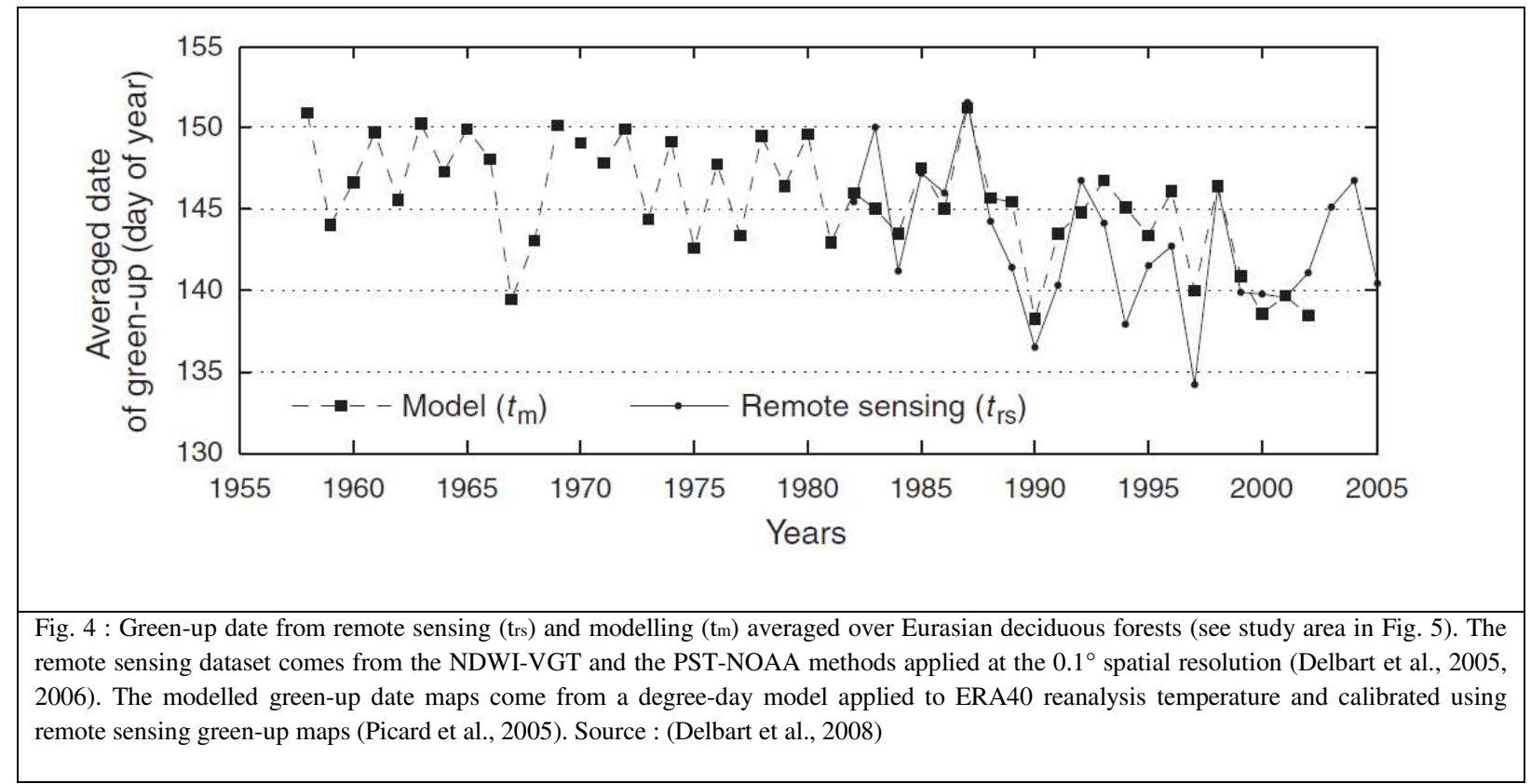




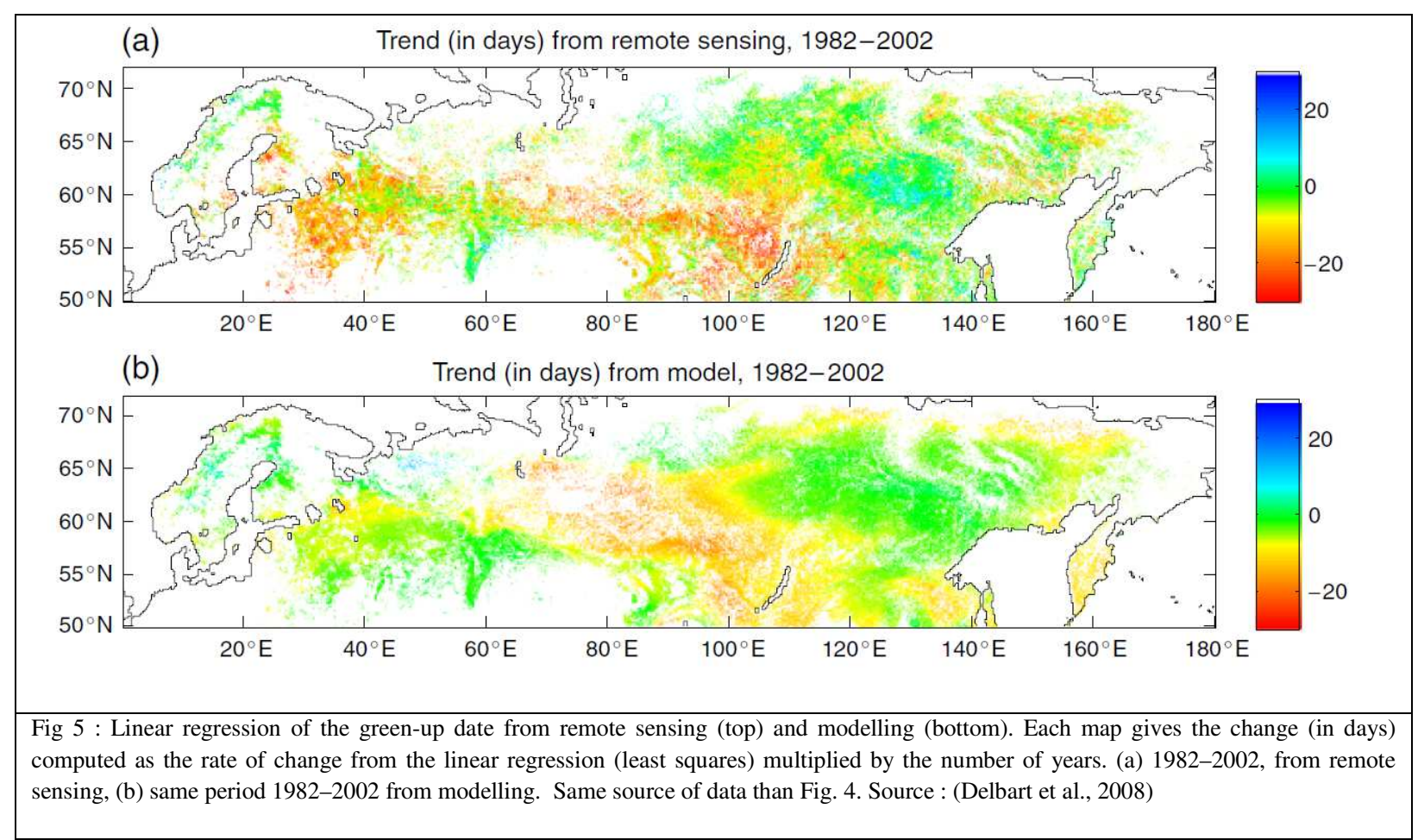

\subsection{Phenological changes in 1998-2017}

The following part aims at completing the previous studies by documenting the interannual variability in forest phenology over the whole circumpolar region during the last twenty years (19982017), with the objective of showing the variability and the trends.

\subsubsection{Dataset and study region}

The phenological algorithm (Delbart et al., 2005) is applied to the SPOT-VEGETATION (VGT) data for the years 1998 to 2013 and to the successor satellite PROBA-V data for the years 2014 to 2017, in order to provide a full 20-year spring phenology time series. Both datasets are provided by VITO (https://www.vito-eodata.be). The PROBA-V data full resolution is $300 \mathrm{~m}$, but here the $1 \mathrm{~km}$ resolution product is used to match the resolution of if predecessor and to follow the same compositing rules. Here, the algorithm is applied at the full SPOT-VGT spatial resolution $\left(0.0089^{\circ}\right)$. The algorithm is run for the years 1998 to 2013 on SPOT-VGT data and on PROBA-V over the years 2014-2017, to obtain one green-up day map each year at the $1 \mathrm{~km}$. This differs from previous time series studies (Delbart \& Picard, 2007; Delbart et al., 2008) for which the SPOT-VGT reflectance data were first averaged at $0.1^{\circ}$. It is important to notice that the PST-NOAA algorithm was calibrated using the results from this $0.1^{\circ}$ aggregated SPOT-VGT dataset. Thus the results from the full resolution SPOT-VGT data did not combine with the PST-NOAA dataset, so that the following analysis will be restricted to $1998-2017$.

The full resolution dataset reveals spatial details that were not visible in the previous version. Moreover, the comparison of the $1 \mathrm{~km}$ resolution green-up dataset with a massive number of phenology ground observations by citizens have revealed that the reliability of the green-up date differs strongly with the dominant landcover types within the remote sensing pixel (Delbart et al., 2015). Especially it was found that pixels of purely agricultural land or as water body by the Global 
Land Cover 2000 (GLC2000) dataset (Bartholomé \& Belward, 2005) should be excluded from the green-up date maps. We then aggregate through local averaging the not-excluded pixels to a spatial resolution ten times lower of the original one. This allows to reduce both the fraction of territory with missing data and the dataset size. Moreover, previous studies have shown that this dataset better matches interannual variability when spatially averaged (Delbart et al., 2008, 2015).

The map of the Köppen-Geiger climate classification (Peel et al., 2007) and the landcover map GLC2000 (Bartholomé \& Belward, 2005) are used to restrict the study area to the circumpolar forests and shrublands (CLC2000 classes 1 to 12) located in a cold or polar climate (Köppen-Geiger zones D and E). The GLC2000 dataset reports a pixel as forest if the tree cover fraction is more that $15 \%$, the used criteria allows to define the current study area as the taiga and the subarctic tundra regions, for which ligneous vegetation is settled but not necessarily dominant. Green-up date reported for evergreen forests is related to the leaf phenology of the sparse deciduous trees.

\subsubsection{Delineating phenoregions}

At large scale the time variations in phenology are often represented through a trend analysis at the pixel level complemented by a spatial average over large regions (e.g. (Schwartz et al., 2006; Delbart et al., 2008; Gonsamo \& Chen, 2016). Both methods have drawbacks: trend analysis results are very much dependant on the time range of the dataset ; spatial averaging over arbitrary regions, like hemisphere (Schwartz et al., 2006; Gonsamo \& Chen, 2016a) or rectangles (Delbart et al., 2008, 2015), results in hiding spatial differences within the considered region and necessarily combines sub-regions of different variability. Recent studies extending the study of the variations in phenology (Gonsamo \& Chen, 2016a; Park et al., 2016) provide maps of the trend that cannot be compared because of different period limits. There is a need to, in addition to the maps of trend, to delineate regions, the so-called "phenoregions", that are homogeneous in terms of interannual variability in phenology, with no hypothesis on the region shape or size. For these regions the interannual variability in phenology will be displayed, with the aim to visualize the variations in phenology for some key regions of interest in the study area, i.e. regions displaying strong trends.

The term "phenoregion" differs from previous occurrence for which the whole annual cycle of spectral indice was used (White et al., 2005). Here, phenoregions are the regions for which the interannual variability of the green-up date are homogeneous. They are delineated from the annual anomalies in the green-up date. The first step consists of substracting the 20-year average green-up date from each annual map to provide a time series of maps of temporal anomaly in phenology, free of spatial gradients. On this time series a k-means classification is conducted with a large and arbitrary number of classes (here, 300 classes). Closely related classes are merged using an ascending hierarchical clustering based on a dissimilarity measure that is 1 minus the correlation between each of the 300 above classes. The classes are then aggregated if their dissimilarity is less than a chosen threshold, here 0.439 , i.e. if their correlation is positive and significant at 0.01 level. 


\subsubsection{Spatial and temporal variability}

The twenty-year average green-up date follows a South to North gradient in Eurasia and a Southwest to North-east gradient in North America, with no difference in averages and distributions between the two continents (Fig. 6). The interannual variability in the green-up date is highly spatially variable, and can take some large values: the temporal amplitude, i.e. the difference between the earliest and latest dates recorded at one pixel, ranges from 20 to 50 days (Fig. 6). The overall direction of changes is summarized through the slope of the linear regression of the green-up date over time. Slope ranges from -0.68 to 0.5 days/year, with a mean value of -0.11 days/year, indicating a moderate trend to an earlier green-up on average over the circumpolar forests during the last twenty years. Using different sensors, metrics and study periods, slightly different trends were found at the circumpolar scale : a small delay of +0.085 days/year over 2000-2014 (Park et al., 2016), or a small advance of -0.23 days/year in 1999-2013 (Gonsamo \& Chen, 2016a).

The spatial distribution of the slope values reveal that the strongest trends are not necessarily found for pixels displaying the strongest variability. However, a relatively clear pattern emerges: several large regions display a delay (e.g. Western boreal Eurasia, most of Canada) while others show an advance (Ural region, a large region including Alaska, Yukon and Canadian North-West territories, Yakoutia, Fennoscandia). 

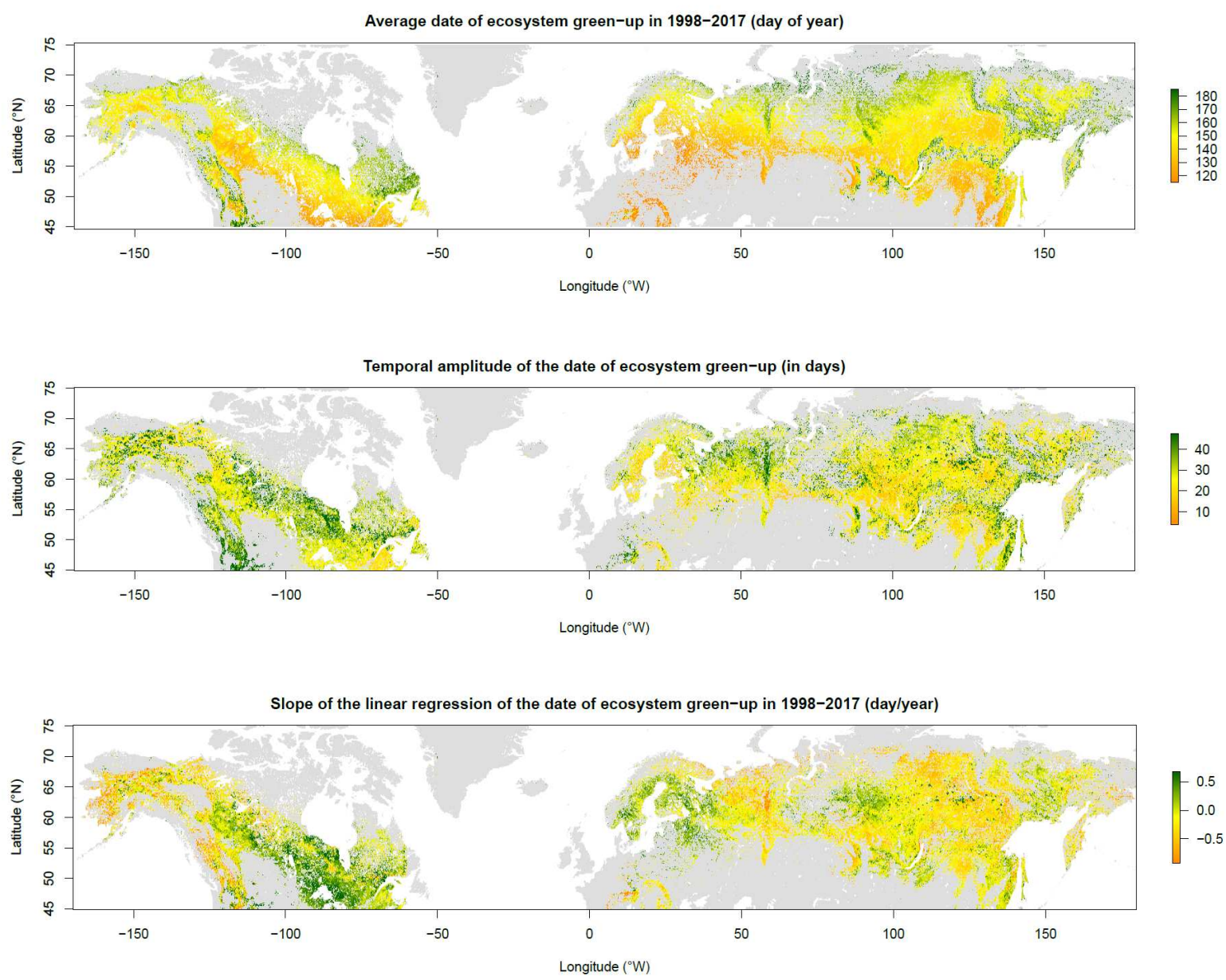

Figure 6 : Summary of spatial and temporal variations in phenology in 1998-2017 as estimated friom the SPOT-VEGETATION and PROBA-V using the NDWI algorithm (Delbart et al., 2005) at the full resolution before data exclusion based on validation (Delbart et al., 2015). Top : 20-year average date of green-up (day of year). Middle : amplitude of the interannual variations (in days). Bottom : slope of the linear regression on chronological time series of the green-up date (days.year ${ }^{-1}$ ).

\subsubsection{Interannual variability at the phenoregion level}

The slope of the linear regression is highly variable spatially. It is also well known that the time limits of the study period have a strong influence on the regression slope of a time series. The green-up date time series for several phenoregions are displayed in Fig 7-9, in order to better understand the slope values, for North America (Fig.7), western boreal Europe (Fig. 8) and boreal Asia (Fig. 9). The selected phenoregions are corresponding to the regions with strong trends. This is possible to identify them since the location of most phenoregions corresponds to an area of rather homogeneous slope. This is not true for one of the selected phenoregions located in central boreal Eurasia, which groups pixels with positive and negative sloped despite correlated interannual variations. The central Eurasia area with positive slope (Fig. 6) is in fact distributed to at least two phenoregions and thus corresponds to at least two modes of variations (Fig. 9). 
Very clearly, it appears that a viewal examination of the time series contradicts the regression analysis, and that for almost none of the regions a clear trend can be identified. This of course matches the interpretation of the associated $p$-value of the regression slope. $p$-values were lower than 0.01 for only $1.9 \%$ of pixels moreover scattered in the study area ; $p$-values were lower than 0.05 for only $8.4 \%$ of pixels, meaning that the interannual variability exceeds the trend. This is true for pheno-regions displaying progressive delay and for the ones showing an advance in green-up dates. The only exception stands for Alaska and North West Canada (Yukon and North-West territories) where the trend to earlier green-up is more robust (Fig. 7).

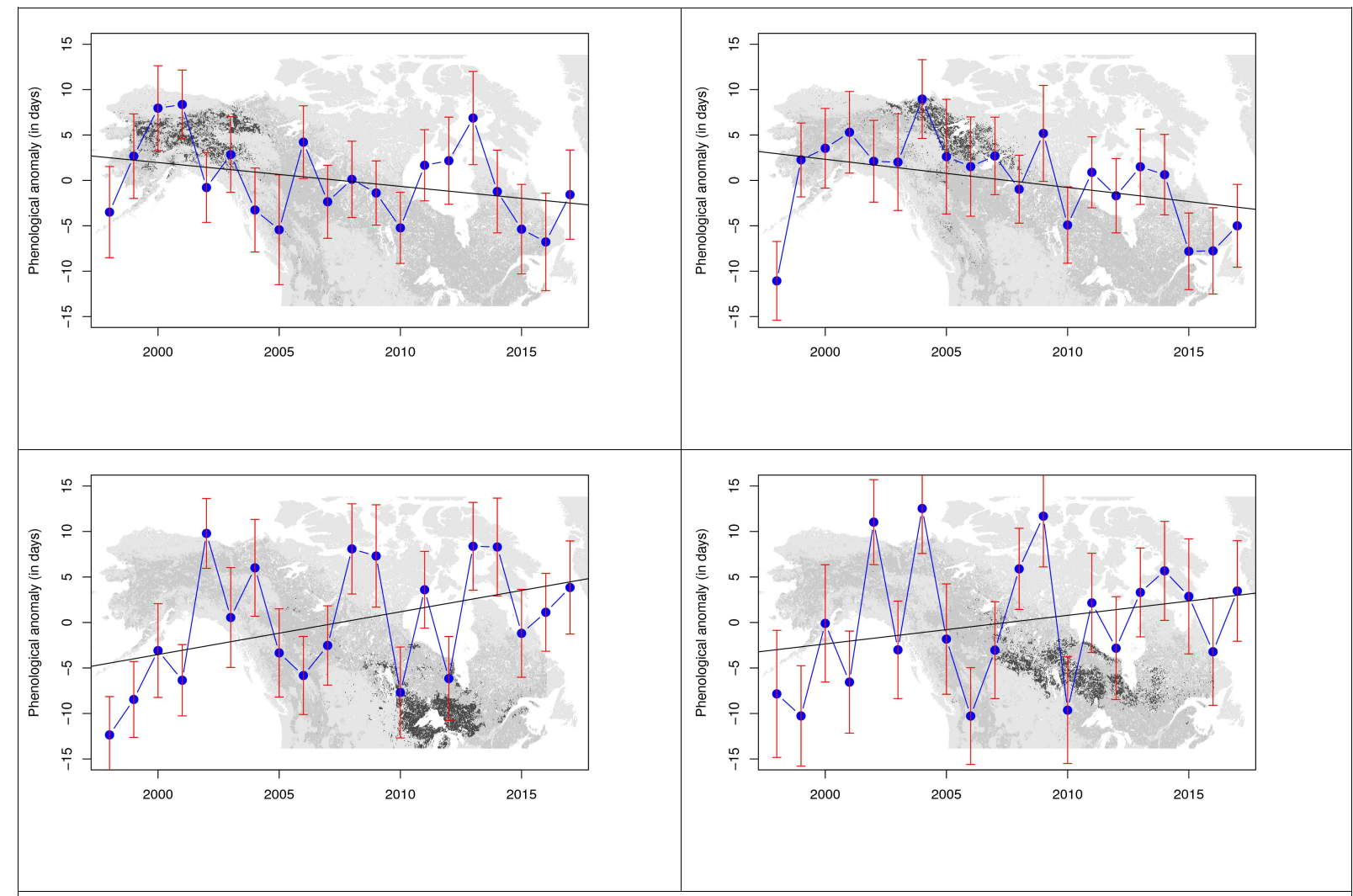

Figure 7: time series of the green-up date averaged at the scale of a selected set of phenoregions in North-America (in day of year). Same source of data than Fig. 6. 


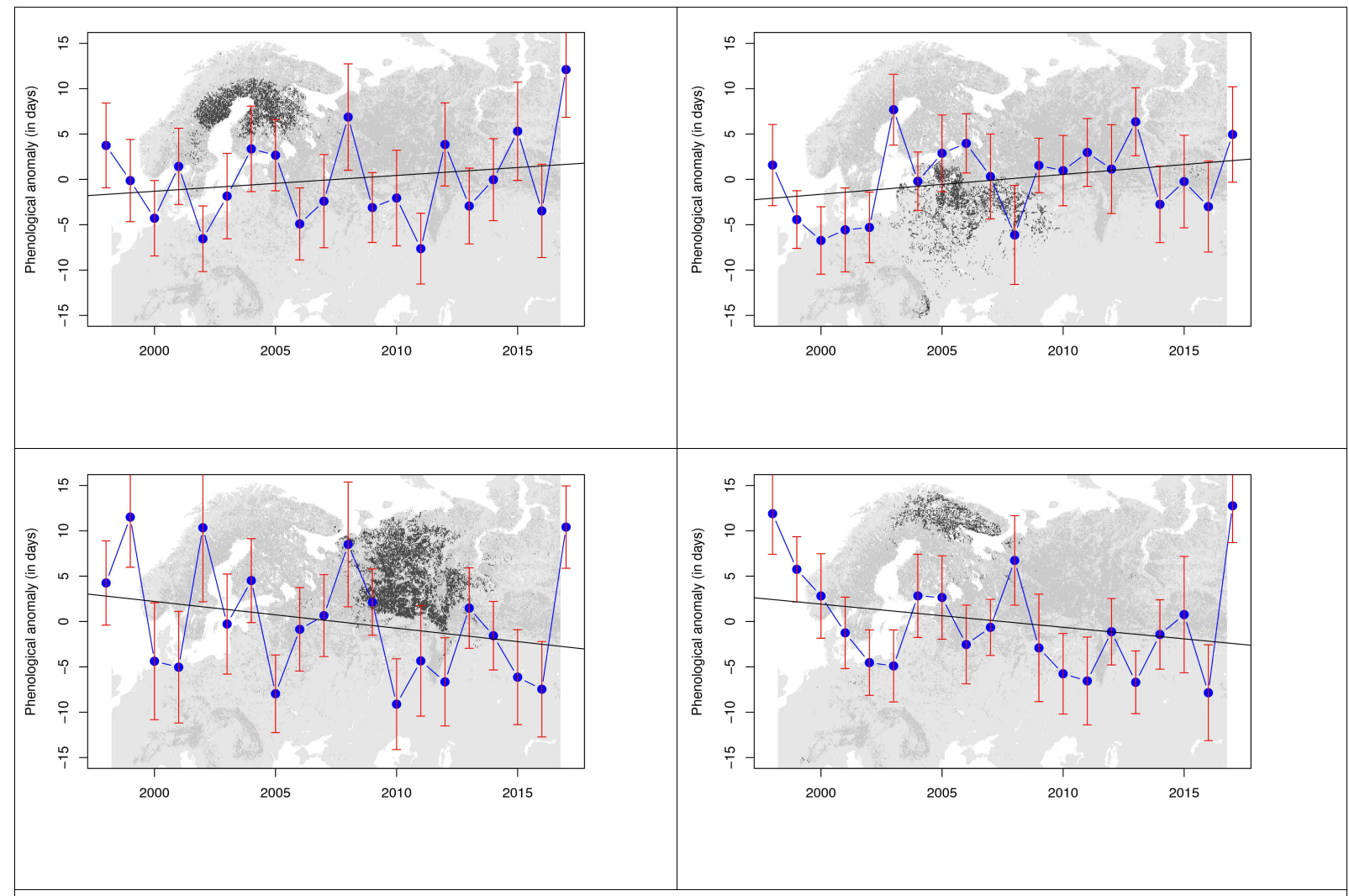

Fig. 8: time series of the green-up date averaged at the scale of a selected set of phenoregions in boreal Europe (in day of year). Same source of data as for Fig. 6. 


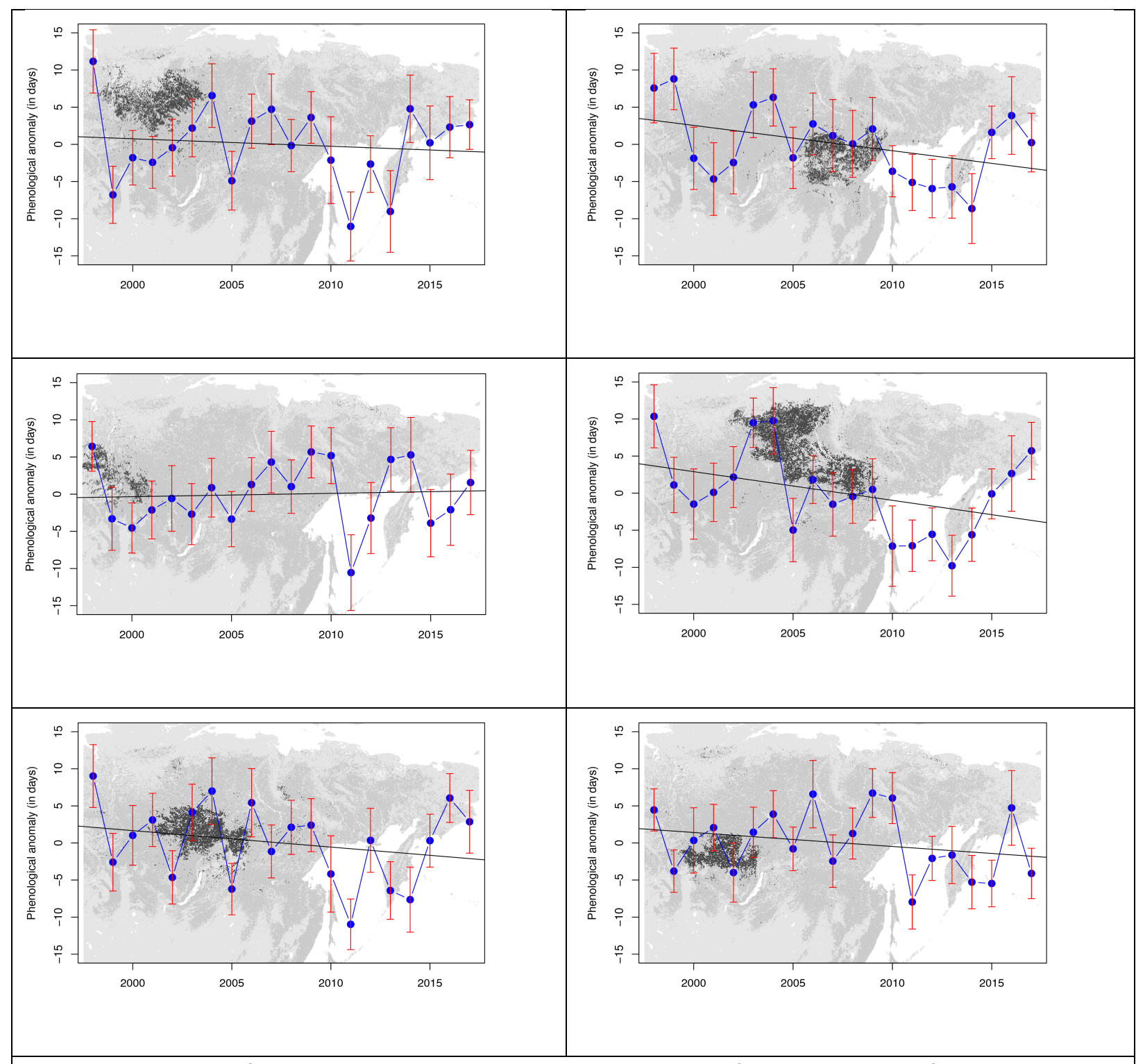

Fig. 9: time series of the green-up date averaged at the scale of a selected set of phenoregions in boreal Asia (in day of year). Same source of data as for Fig. 6.

\subsection{Summary}

In the northern regions, the last twenty years do not display a clear and significant trend in the spring green-up date, relative to the interannual variability in green-up date, except for the North-West North America. Contrarily, the previous period (1982-1999) has shown a strong trend to earlier spring (Park et al., 2016), i.e. a 5 day shift when averaged at a continental scale. This change corresponded to a climate shift (Buermann, 2016), and linked to temperature warming as it can be reproduced by a temperature based model (Delbart et al., 2008). Other trends to earlier spring were found locally (Delbart et al., 2008). This 5-day shift is the most persistent feature in the phenology time series. The lack of trend since then also indicates the date of green-up has not recovered to the values prior to 1987 . 
In addition to this shift in green-up date, the key point is the interannual variability. The section below discusses its effect over the annual carbon budget in the boreal ecosystems. 


\section{Phenology and ecosystem carbon budget}

Phenology is considered as one of the essential biodiversity variables (Pereira et al., 2013) while leaf area index and its seasonal variations is listed as one the essential climate variables (Bojinski et al., 2014). Phenology is widely studied because of its impacts to both ecological and climatic processes. For example, phenological interannual variability that differs among species affects several ecosystems functions, like the plant-pollinators relationships (Kiers et al., 2010) or the trophic networks (Both et al., 2009). In the northern environments, trophic mismatch due to differentiated phenological changes between forage plants and herbivories lead to decrease the reproduction success rates of caribous and reindeers (Post et al., 2008; Post \& Forchhammer, 2008) which is further accented by changes in phenology of harassing insects (Vors \& Boyce, 2009). Phenology is also one essential trait for understanding and modelling the species spatial current and future spatial distribution (Morin et al., 2008; Chuine, 2010).

As mentioned above, the large-scale lengthening of the growing season revealed by remote sensing (Myneni et al., 1997) matched the change in the atmospheric carbon dioxide seasonality changes (Keeling et al., 1996). About half of the carbon dioxide anthropogenic emission accumulates in the atmospheric, while about one quarter is absorbed by the ocean and the last quarter by the continental ecosystems (Le Quéré et al., 2014a), northern ecosystems being one of the carbon sinks that mitigates the rise of atmospheric CO2 concentration (Forkel et al., 2016). In addition to the structural and functional changes affecting vegetation, the lengthening of the growing season in the northern ecosystems is considered among the main processes explaining the continental carbon sink (Graven et al., 2013; Le Quéré et al., 2014b; Buermann, 2016; Forkel et al., 2016), as the increase in the annual gross carbon uptake by ecosystems due to an lengthening growing season is only partially offset by the increase in respiration at autumn (Richardson et al., 2010), so that the net carbon uptake increases with the length of the growing season (Baldocchi et al., 2001).

However some contradictory results exist (Buermann, 2013) as the growing season lengthening does not necessarily transfer into an increased annual net productivity because of water stress (White \& Nemani, 2003) or increased soil respiration (Goulden et al., 1998). Spring advance was even found associated with a decrease in annual carbon uptake measured at the Kitalik station in the Siberian arctic (Parmentier et al., 2011). Remote sensing has revealed a complex geographical patterns of the correlation between the respective dates of spring and autumn: for large regions of Canada and Siberia, early autumn was associated with early spring which reduced the influence of the date of the beginning of spring on the growing season length (Liu et al., 2016). This result was also found in some temperate forests (Keenan, 2015). However, the inverse relationship was found for other regions in Canada and Siberia (Liu et al., 2016). Combining passive microwave and optical remote sensing also revealed that early spring (and early snowmelt) leads to decreased ecosystem greenness in summer in parts of Siberia (Grippa et al., 2005). Overall these results indicate a complex relationship between phenology and annual carbon uptake, which cannot be separated from other processes affecting the vegetation functioning or the water balance. Therefore our efforts have mainly concentrated on improving dynamic vegetation models (DVM) that simulate a cascade of processes involved in carbon uptake and release, energy and water exchanges, and plant growth.

The maps of green-up dates have been used to calibrate the modeling of phenology in the Sheffield Dynamic Vegetation Model (Woodward et al., 1995) aiming to simulate the carbon budget of Siberia 
ecosystems (Picard et al., 2005). Phenological models aim at predicting the date of budburst from daily air temperature time series. The model that was used is the degree-day model to predict the date of budburst as the date when the cumulative (from the $1^{\text {st }}$ January) difference between the daily temperature and a fixed base-temperature reaches a threshold value. Both the base-temperature and the threshold were calibrated (Picard et al., 2005). Other three models including the chilling requirement, i.e. the need for a cold period to release the dormancy, did not display better agreement with remote sensing than the simpler degree-day model, probably because the need for cold was always fulfilled in the central Siberia. The calibration has consisted in determining the set of model parameters that maximized the agreement with the remote sensing maps (Picard et al., 2005). The modeled budburst date was compared to ground observations at various sites in boreal Eurasia located inside or outside the calibration area (Fig.10) (Delbart et al., 2008). Remarkably the RMSE was 7.3 days, with no bias, which is one day better that the agreement between the remote sensing green-up date and the ground observations. The model was also shown to perform as well for tundra shrubs than for taiga trees, and as well as phenology models designed specifically for tundra (Fig. 11) (Delbart \& Picard, 2007). This model can be used across the taiga-tundra ecotone even for simulations under future climate if the ecotone is simulated to move.

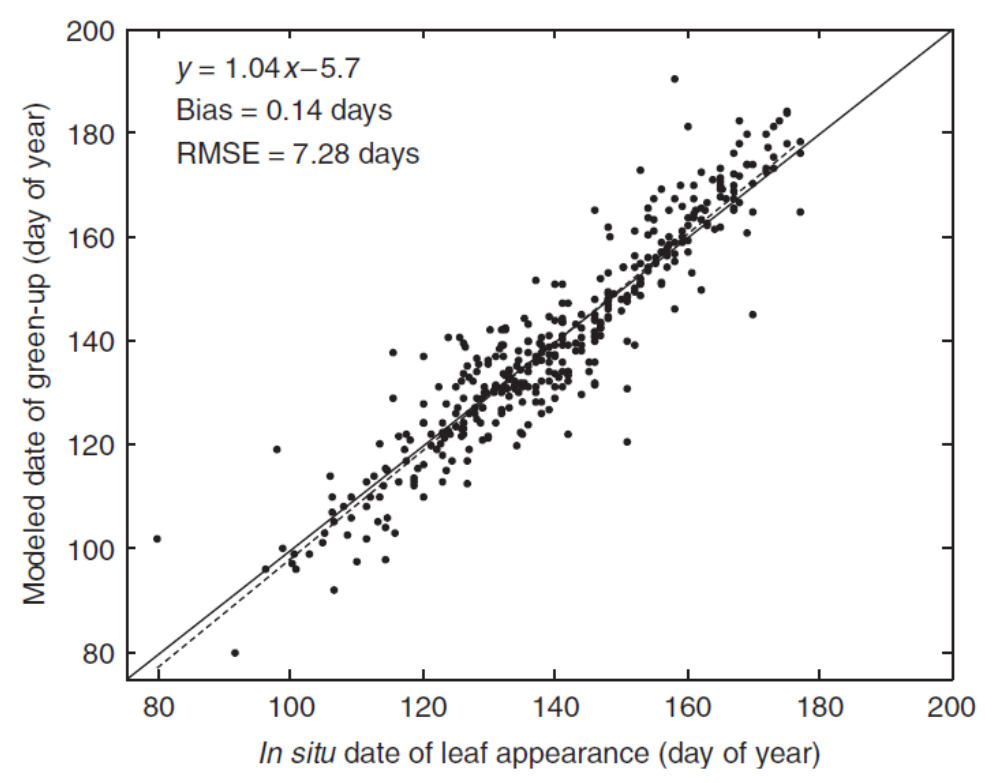

Fig. 10 : Modelled leaf-out dates vs. in situ leaf appearance dates observed at ten locations in boreal Eurasia. The model is a degree-day model applied to temperature time series from the ERA40 reanalysis dataset (Picard et al., 2005). Source: (Delbart et al., 2008). 


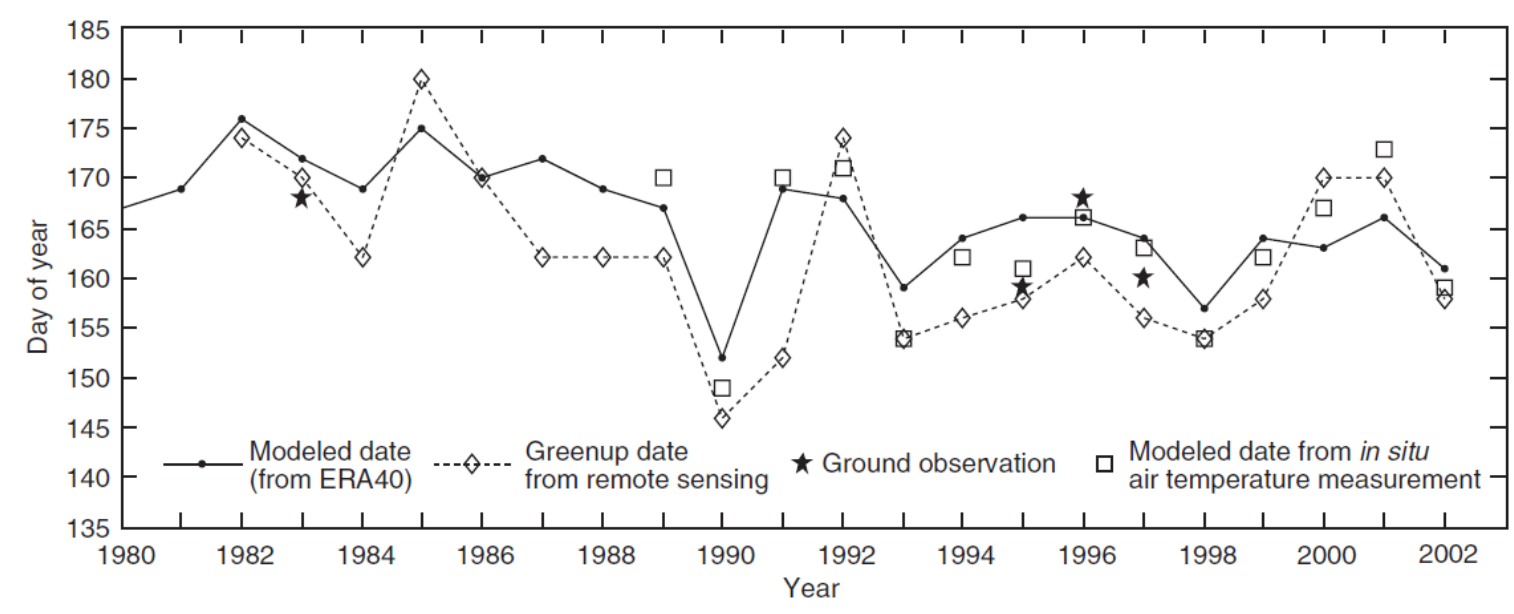

Fig 11 : In situ dates of leaf appearance, simulated green-up dates (Picard et al., 2005) and remote sensing green-up dates from the NDWI-VGT and PST-NOAA methods (Delbart et al., 2005, 2006) at the Toolik Station. Source : (Delbart \& Picard, 2007)

Sensitivity study showed that a one day bias in the modelled green-up date would translate to a $2.2 \%$ error on the annual net primary productivity for the central Siberia study area (Picard et al., 2005). Removing the radiometric effect of the snowmelt on the green-up date detection had therefore led to a decrease in the annual NPP uncertainty. The same phenology model was introduced in a second DVM, SEIB-DVM (Sato et al., 2007, 2010), that differs from the first model by simulating the growth of individuals. Simulations under increasing temperature has revealed that for Eastern Siberian larch forests the lengthening of the growing season was accompanied by an increase in water stress in summer and in the carbon release through respiration, resulting altogether in a decrease of the annual NPP, which was also reported in the above mentionned studies (Goulden et al., 1998; Parmentier et al., 2011; Liu et al., 2016).

In conclusion, the impact of phenological responses to temperature variations on the annual productivity of boreal ecosystems is still unclear and strongly depends on regional and local conditions, and especially depends on all processes affecting the water availability. It does not seem that a specific homogeneous effect of phenology can be clearly identified. Phenology is a temperature driven process, among other climate driven processes that must all be modelled taking into account the regional specificities of the interplay between soil, water and carbon cycles. To this end, an arctic-specific version of a third land surface model (LSM), ORCHIDEE (Krinner et al., 2005; Guimberteau et al., 2018), was recently designed by incorporating specific developments of the processes related to permafrost, snow, plant functional type distribution (Ottlé et al., 2013) and through a rational selection of key parameters to be calibrated (Dantec-Nédélec et al., 2017b). This version was evaluated through a comparison to a large set of ground observations, fluxes time series, and satellite derived parameters including phenology and leaf area index (Dantec-Nédélec, 2017a), and will be used to explore the future of the carbon balance. Besides, it must be noticed that actual plant productivity, and not only greenness, may be monitored by other types of remote sensing like 
solar-induced fluorescence, leading to new insight into boreal ecosystem carbon budget (Walther et al., 2016).

\section{Conclusion}

This chapter has summarized the results obtained in three directions. The first one concerns the methods to measure and map the green-up date of boreal ecosystems without signal disturbance by snowmelt, and has established its link to the actual tree leaf appearance date. It was also shown that the interannual variations in the green-up date correspond to the phenology of a whole community of plants. The second one is the analysis of the time variations in green-up date, that has revealed a 5-day shift to earlier spring between 1987 and 1990. Before 1987 and after 1990, trends can be found locally but not at large scale, as interannual variability in the green-up date exceeds its trend. The third study direction is the integration of phenology in ecosystem models designed to simulate the carbon, energy and water exchanges between the ecosystem and the atmosphere. Remote sensing green-up date maps were successfully used to calibrate a phenology model that was unbiased and able to reproduce spatial and temporal variations in phenology from the daily temperature time series. The integration of such a model was crucial as it avoids bias in the simulated productivity, as the green-up date may influence the growing season length and thus the annual carbon budget. However, because the annual carbon budget depends only partly on phenology, and because earlier spring may induce an early depletion of water resources, there is no consensus of the effect of phenology on annual carbon budget for the boreal ecosystems. Improving all processes involved in carbon and water cycles, in soils and vegetation, in ecosystem models is crucial. Besides, improvements in the remote sensing of other variables are necessary. Among the variables directly related to vegetation can be listed as the leaf area index (Kobayashi et al., 2010), vegetation stress and actual productivity (Walther et al., 2016), or the date of senescence. The attempts to derive a date of senescence from spectral indices failed (Delbart et al., 2005). Results reported in the chapter XXX by Yongwon Kim show that the snow also disturbs the retrieval of the senescence date. Other teams display better agreement of the senescence date with ground measurements (e.g. Jin \& Eklundh, 2014). However, it is difficult to select a single date from the remote sensing time series to represent senescence because it is a gradual process at all scales from the leaf, the tree to the community that is observable in the medium resolution remote sensing pixel. Dense time series of high spatial resolution optical remote sensing images that are now available may partly solve this issue by zooming the phenology studies nearly up to the individuals trees.

\section{Acknowledgements}

Many thanks to the authors and co-authors of the published results that are summarized in this chapter, and in particular Elisabeth Beaubien, Sarah Dantec-Nédélec, Dennis Dye, Manuela Grippa, Laurent Kergoat, Hideki Kobayashi, Thuy Le Toan, Fabienne Maignan, Catherine Ottlé, Ghislain Picard, Hisashi Sato and Sergio Vicente Serrano.

Thanks to VITO for providing SPOT-VEGETATION and PROBA-V data. The algorithm for green-up date extraction from PROBA-V data was implemented on the VITO MEP.

This chapter is dedicated to the memory of Rikie Suzuki. 


\section{Réferences}

Badeck, F.-W., Bondeau, A., Böttcher, K., Doktor, D., Lucht, W., Schaber, J., \& Sitch, S. (2004) Responses of spring phenology to climate change. New Phytologist, 162, 295-309.

Baldocchi, D., Falge, E., Gu, L., et al. (2001) FLUXNET: A New Tool to Study the Temporal and Spatial Variability of Ecosystem-Scale Carbon Dioxide, Water Vapor, and Energy Flux Densities. Bulletin of the American Meteorological Society, 82, 2415-2434.

Bartholomé, E. \& Belward, A.S. (2005) GLC2000: A new approach to global land cover mapping from earth observation data. International Journal of Remote Sensing, 26, 1959-1977.

Beaubien, E.G. \& Hamann, A. (2011a) Plant phenology networks of citizen scientists: Recommendations from two decades of experience in Canada. International Journal of Biometeorology, 55, 833-841.

Beaubien, E. \& Hamann, A. (2011b) Spring flowering response to climate change between 1936 and 2006 in Alberta, Canada. BioScience, 61, 514-524.

Beck, P.S.A., Atzberger, C., Høgda, K.A., Johansen, B., \& Skidmore, A.K. (2006) Improved monitoring of vegetation dynamics at very high latitudes: A new method using MODIS NDVI. Remote Sensing of Environment, 100, 321-334.

Bellard, C., Bertelsmeier, C., Leadley, P., Thuiller, W., \& Courchamp, F. (2012) Impacts of climate change on the future of biodiversity. Ecology letters, 15, 365-377.

Bojinski, S., Verstraete, M., Peterson, T.C., Richter, C., Simmons, A., \& Zemp, M. (2014) The Concept of Essential Climate Variables in Support of Climate Research, Applications, and Policy. Bulletin of the American Meteorological Society, 95, 1431-1443.

Both, C., Van Asch, M., Bijlsma, R.G., Van Den Burg, A.B., \& Visser, M.E. (2009) Climate change and unequal phenological changes across four trophic levels: Constraints or adaptations? Journal of Animal Ecology, 78, 73-83.

Buermann, J.L. (2016) Climate-driven shifts in continental net primary production implicated as a driver of a recent abrupt increase in the land carbon sink. Biogeosciences, 13, 1597-1607.

Buermann, M. (2013) Earlier springs decrease peak summer productivity in North American boreal forests. Environmental Research Letters, 8, .

Chuine, I. (2010) Why does phenology drive species distribution? Philosophical Transactions of the Royal Society B: Biological Sciences, 365, 3149-3160.

Colombo, U.M. (2011) Phenological monitoring of grassland and larch in the Alps from Terra and Aqua MODIS images. Italian Journal of Remote Sensing / Rivista Italiana di Telerilevamento, 43, 83-96.

Dantec-Nédélec, S. (2017) Evaluation multi-échelle des bilans d'énergie et d'eau du modèle ORCHIDEE sur la Sibérie et leur réponse à l'évolution du climat. Paris Saclay, 
Delbart, N., Beaubien, E., Kergoat, L., \& Le Toan, T. (2015) Comparing land surface phenology with leafing and flowering observations from the PlantWatch citizen network. Remote Sensing of Environment, 160, 273-280.

Delbart, N., Kergoat, L., Le Toan, T., Lhermitte, J., \& Picard, G. (2005) Determination of phenological dates in boreal regions using normalized difference water index. Remote Sensing of Environment, 97, 26-38.

Delbart, N., Le Toan, T., Kergoat, L., \& Fedotova, V. (2006) Remote sensing of spring phenology in boreal regions: A free of snow-effect method using NOAA-AVHRR and SPOT-VGT data (19822004). Remote Sensing of Environment, 101, 52-62.

Delbart, N. \& Picard, G. (2007) Modeling the date of leaf appearance in low-arctic tundra. Global Change Biology, 13, 2551-2562.

Delbart, N., Picard, G., Le Toan, T., Kergoat, L., Quegan, S., Woodward, I., Dye, D., \& Fedotova, V. (2008a) Spring phenology in boreal Eurasia over a nearly century time scale. Global Change Biology, 14, 603-614.

Delbart, N., Picard, G., Le Toan, T., Kergoat, L., Quegan, S., Woodward, I., Dye, D., \& Fedotova, V. (2008b) Spring phenology in boreal Eurasia over a nearly century time scale. Global Change Biology, 14, 603-614.

Dethier, B.E., Ashley, M.D., Blair, B.O., Caprio, J.M., Hopp, R.J., \& Rouse Jr, J. (1973) Phenology satellite experiment.[detection of brown wave and green wave in north-south corridors of United States]. .

Duchemin, B., Goubier, J., \& Courrier, G. (1999) Monitoring phenological key stages and cycle duration of temperate deciduous forest ecosystems with NOAA/AVHRR data. Remote Sensing of Environment, 67, 68-82.

Dunn, A.H. \& de Beurs, K.M. (2011) Land surface phenology of North American mountain environments using moderate resolution imaging spectroradiometer data. Remote Sensing of Environment, 115, 1220-1233.

Dye, D.G. \& Tucker, C.J. (2003) Seasonality and trends of snow-cover, vegetation index, and temperature in northern Eurasia. Geophysical Research Letters, 30, 58-1.

Forkel, M., Carvalhais, N., Rödenbeck, C., Keeling, R., Heimann, M., Thonicke, K., Zaehle, S., \& Reichstein, M. (2016) Enhanced seasonal CO2 exchange caused by amplified plant productivity in northern ecosystems. Science, 351, 696-699.

Gonsamo, A. \& Chen, J.M. (2016a) Circumpolar vegetation dynamics product for global change study. Remote Sensing of Environment, 182, 13-26.

Gonsamo, A. \& Chen, J.M. (2016b) Circumpolar vegetation dynamics product for global change study. Remote Sensing of Environment, 182, 13-26.

Gonsamo, C. (2013) Citizen Science: Linking the recent rapid advances of plant flowering in Canada with climate variability. Scientific Reports, 3, . 
Goulden, M.L., Wofsy, S.C., Harden, J.W., Trumbore, S.E., Crill, P.M., Gower, S.T., Fries, T., Daube, B.C., Fan, S.-M., Sutton, D.J., Bazzaz, A., \& Munger, J.W. (1998) Sensitivity of boreal forest carbon balance to soil thaw. Science, 279, 214-217.

Graven, H.D., Keeling, R.F., Piper, S.C., Patra, P.K., Stephens, B.B., Wofsy, S.C., Welp, L.R., Sweeney, C., Tans, P.P., Kelley, J.J., Daube, B.C., Kort, E.A., Santoni, G.W., \& Bent, J.D. (2013) Enhanced Seasonal Exchange of CO2 by Northern Ecosystems Since 1960. Science, 341, 1085-1089.

Grippa, M., Mognard, N., \& Le Toan, T. (2005) Comparison between the interannual variability of snow parameters derived from SSM/I and the Ob river discharge. Remote Sensing of Environment, 98, 35-44.

Guan, S.-J. (2014) Deriving vegetation phenological time and trajectory information over africa using seviri daily LAI. IEEE Transactions on Geoscience and Remote Sensing, 52, 1113-1130.

Guimberteau, M., Zhu, D., Maignan, F., Huang, Y., Chao, Y., Dantec-Nédélec, S., Ottlé, C., Jornet-Puig, A., Bastos, A., \& Laurent, P. (2018) ORCHIDEE-MICT (v8. 4.1), a land surface model for the high latitudes: model description and validation. Geoscientific Model Development, 11, 121.

Guyon, J.-P. (2011) Monitoring elevation variations in leaf phenology of deciduous broadleaf forests from SPOT/VEGETATION time-series. Remote Sensing of Environment, 115, 615-627.

Hakkinen, R., Linkosalo, T., \& Hari, P. (1995) Methods for combination phenological time series: Application to bud burst in birch (Betula pendula) in central Finland for the period 18961955. Tree Physiology, 15, 721-726.

Helman, D. (2018) Land surface phenology: What do we really "see" from space? Science of The Total Environment, 618, $665-673$.

Hinzman, L.D., Bettez, N.D., Bolton, W.R., et al. (2005) Evidence and implications of recent climate change in Northern Alaska and other Arctic regions. Climatic Change, 72, 251-298.

Holben, B.N. (1986) Characteristics of maximum-value composite images from temporal AVHRR data. International Journal of Remote Sensing, 7, 1417-1434.

IPCC (2013) Climate Change 2013: The Physical Science Basis. Contribution of Working Group I to the Fifth Assessment Report of the Intergovernmental Panel on Climate Change. Cambridge University Press, Cambridge, United Kingdom and New York, NY, USA.

James, M.E. \& Kalluri, S.N.V. (1994) The pathfinder AVHRR land data set: an improved coarse resolution data set for terrestrial monitoring. International Journal of Remote Sensing, 15, 3347-3363.

Jin, H. \& Eklundh, L. (2014) A physically based vegetation index for improved monitoring of plant phenology. Remote Sensing of Environment, 152, 512-525.

Jin, H., Jönsson, A.M., Bolmgren, K., Langvall, O., \& Eklundh, L. (2017) Disentangling remotely-sensed plant phenology and snow seasonality at northern Europe using MODIS and the plant phenology index. Remote Sensing of Environment, 198, 203-212.

Justice, B.O., Holben, B.N., \& Gwynne, M.D. (1986) Monitoring east african vegetation using AVHRR data. International Journal of Remote Sensing, 7, 1453-1474. 
Justice, C.O., Townshend, J.R.G., Holben, A.N., \& Tucker, C.J. (1985) Analysis of the phenology of global vegetation using meteorological satellite data. International Journal of Remote Sensing, 6, 1271-1318.

Keeling, C.D., Chin, J.F.S., \& Whorf, T.P. (1996) Increased activity of northern vegetation inferred from atmospheric CO2 measurements. Nature, 382, 146-149.

Keenan, A.D. (2015) The timing of autumn senescence is affected by the timing of spring phenology: Implications for predictive models. Global Change Biology, 21, 2634-2641.

Kiers, E.T., Palmer, T.M., Ives, A.R., Bruno, J.F., \& Bronstein, J.L. (2010) Mutualisms in a changing world: An evolutionary perspective. Ecology Letters, 13, 1459-1474.

Krinner, G., Viovy, N., de Noblet-Ducoudré, N., Ogée, J., Polcher, J., Friedlingstein, P., Ciais, P., Sitch, S., \& Prentice, I.C. (2005) A dynamic global vegetation model for studies of the coupled atmosphere-biosphere system. Global Biogeochemical Cycles, 19, 1-33.

Le Quéré, C., Peters, G.P., Andres, R.J., et al. (2014a) Global carbon budget 2013. Earth System Science Data, 6, 235-263.

Le Quéré, C., Peters, G.P., Andres, R.J., et al. (2014b) Global carbon budget 2013. Earth System Science Data, 6, 235-263.

Liang, L., Schwartz, M.D., \& Fei, S. (2011) Validating satellite phenology through intensive ground observation and landscape scaling in a mixed seasonal forest. Remote Sensing of Environment, 115, 143-157.

Liu, Q., Fu, Y.H., Zhu, Z., Liu, Y., Liu, Z., Huang, M., Janssens, I.A., \& Piao, S. (2016) Delayed autumn phenology in the Northern Hemisphere is related to change in both climate and spring phenology. Global change biology, 22, 3702-3711.

Menzel, A. (2000) Trends in phenological phases in Europe between 1951 and 1996. International Journal of Biometeorology, 44, 76-81.

Meroni, M., Verstraete, M.M., Rembold, F., Urbano, F., \& Kayitakire, F. (2014) A phenology-based method to derive biomass production anomalies for food security monitoring in the Horn of Africa. International Journal of Remote Sensing, 35, 2472-2492.

Misra, G., Buras, A., \& Menzel, A. (2016) Effects of Different Methods on the Comparison between Land Surface and Ground Phenology-A Methodological Case Study from South-Western Germany. Remote Sensing, 8, .

Morin, X., Viner, D., \& Chuine, I. (2008) Tree species range shifts at a continental scale: New predictive insights from a process-based model. Journal of Ecology, 96, 784-794.

Morisette, J.T., Richardson, A.D., Knapp, A.K., Fisher, J.I., Graham, E.A., Abatzoglou, J., Wilson, B.E., Breshears, D.D., Henebry, G.M., Hanes, J.M., \& Liang, L. (2009) Tracking the rhythm of the seasons in the face of global change: Phenological research in the 21 st century. Frontiers in Ecology and the Environment, 7, 253-260.

Moulin, S., Kergoat, L., Viovy, N., \& Dedieu, G. (1997) Global-scale assessment of vegetation phenology using NOAA/AVHRR satellite measurements. Journal of Climate, 10, 1154-1170. 
Myneni, R.B., Keeling, C.D., Tucker, C.J., Asrar, G., \& Nemani, R.R. (1997) Increased plant growth in the northern high latitudes from 1981 to 1991. Nature, 386, 698-702.

Myneni, R.B., Tucker, C.J., Asrar, G., \& Keeling, C.D. (1998) Interannual variations in satellite-sensed vegetation index data from 1981-1991. Journal of Geophysical Research D: Atmospheres, 103, 6145-6160.

Ottlé, C., Lescure, J., Maignan, F., Poulter, B., Wang, T., \& Delbart, N. (2013) Use of various remote sensing land cover products for plant functional type mapping over Siberia. Earth System Science Data, 5, 331-348.

Park, T., Ganguly, S., Tømmervik, H., Euskirchen, E.S., Høgda, K.-A., Karlsen, S.R., Brovkin, V., Nemani, R.R., \& Myneni, R.B. (2016) Changes in growing season duration and productivity of northern vegetation inferred from long-term remote sensing data. Environmental Research Letters, 11, 084001.

Parmentier, F.J.W., Van Der Molen, M.K., Van Huissteden, J., Karsanaev, S.A., Kononov, A.V., Suzdalov, D.A., Maximov, T.C., \& Dolman, A.J. (2011) Longer growing seasons do not increase net carbon uptake in the northeastern Siberian tundra. Journal of Geophysical Research: Biogeosciences, 116, .

Parmesan, C. \& Yohe, G. (2003) A globally coherent fingerprint of climate change impacts across natural systems. Nature, 421, 37-42.

Peel, M.C., Finlayson, B.L., \& McMahon, T.A. (2007) Updated world map of the Köppen-Geiger climate classification. Hydrology and Earth System Sciences, 11, 1633-1644.

Pennec, A., Gond, V., \& Sabatier, D. (2011) Tropical forest phenology in French Guiana from MODIS time series. Remote Sensing Letters, 2, 337-345.

Pereira, H.M., Ferrier, S., Walters, M., et al. (2013) Essential Biodiversity Variables. Science, 339, 277278.

Picard, G., Quegan, S., Delbart, N., Lomas, M.R., Le Toan, T., \& Woodward, F.I. (2005) Bud-burst modelling in Siberia and its impact on quantifying the carbon budget. Global Change Biology, 11, 2164-2176.

Post, E. \& Forchhammer, M.C. (2008) Climate change reduces reproductive success of an Arctic herbivore through trophic mismatch. Philosophical Transactions of the Royal Society of London B: Biological Sciences, 363, 2367-2373.

Post, E., Forchhammer, M.C., Bret-Harte, M.S., Callaghan, T.V., Christensen, T.R., Elberling, B., Fox, A.D., Gilg, O., Hik, D.S., \& Høye, T.T. (2009) Ecological dynamics across the Arctic associated with recent climate change. science, 325, 1355-1358.

Post, E., Pedersen, C., Wilmers, C.C., \& Forchhammer, M.C. (2008) Warming, plant phenology and the spatial dimension of trophic mismatch for large herbivores. Proceedings of the Royal Society of London B: Biological Sciences, 275, 2005-2013.

Pouliot, I. (2011) Evaluation of compositing period and AVHRR and MERIS combination for improvement of spring phenology detection in deciduous forests. Remote Sensing of Environment, 115, 158-166. 
Rea, J. \& Ashley, M. (1976) Phenological evaluations using Landsat-1 sensors. International Journal of Biometeorology, 20, 240-248.

Richardson, A.D., Black, T.A., Ciais, P., et al. (2010) Influence of spring and autumn phenological transitions on forest ecosystem productivity. Philosophical Transactions of the Royal Society B: Biological Sciences, 365, 3227-3246.

Richardson, M. (2013) Climate change, phenology, and phenological control of vegetation feedbacks to the climate system. Agricultural and Forest Meteorology, 169, 156-173.

Root, T.L., Price, J.T., Hall, K.R., Schneider, S.H., Rosenzweig, C., \& Pounds, J.A. (2003) Fingerprints of global warming on wild animals and plants. Nature, 421, 57-60.

Sato, H., Itoh, A., \& Kohyama, T. (2007) SEIB-DGVM: A new Dynamic Global Vegetation Model using a spatially explicit individual-based approach. Ecological Modelling, 200, 279-307.

Sato, H., Kobayashi, H., \& Delbart, N. (2010) Simulation study of the vegetation structure and function in eastern Siberian larch forests using the individual-based vegetation model SEIBDGVM. Forest Ecology and Management, 259, 301-311.

Schwartz, M.D. (1998) Green-wave phenology [4]. Nature, 394, 839-840.

Schwartz, M.D., Ahas, R., \& Aasa, A. (2006) Onset of spring starting earlier across the Northern Hemisphere. Global Change Biology, 12, 343-351.

Schwartz, M.D., Reed, B.C., \& White, M.A. (2002) Assesing satellite-derived start-of-season measures in the conterminous USA. International Journal of Climatology, 22, 1793-1805.

Shabanov, N.V., Zhou, L., Knyazikhin, Y., Myneni, R.B., \& Tucker, C.J. (2002) Analysis of interannual changes in northern vegetation activity observed in AVHRR data from 1981 to 1994. IEEE Transactions on Geoscience and Remote Sensing, 40, 115-130.

Solomon, S. (2007) Climate change 2007-the physical science basis: Working group I contribution to the fourth assessment report of the IPCC. Cambridge University Press,

Soudani, S. (2008) Evaluation of the onset of green-up in temperate deciduous broadleaf forests derived from Moderate Resolution Imaging Spectroradiometer (MODIS) data. Remote Sensing of Environment, 112, 2643-2655.

Suzuki, R., Kobayashi, H., Delbart, N., Asanuma, J., \& Hiyama, T. (2011) NDVI responses to the forest canopy and floor from spring to summer observed by airborne spectrometer in eastern Siberia. Remote Sensing of Environment, 115, 3615-3624.

Suzuki, R., Nomaki, T., \& Yasunari, T. (2003) West-east contrast of phenology and climate in northern Asia revealed using a remotely sensed vegetation index. International Journal of Biometeorology, 47, 126-138.

Thompson, B.G. (2015) Using phase-spaces to characterize land surface phenology in a seasonally snow-covered landscape. Remote Sensing of Environment, 166, 178-190.

Thompson, J.A. \& Paull, D.J. (2017) Assessing spatial and temporal patterns in land surface phenology for the Australian Alps (2000-2014). Remote Sensing of Environment, 199, 1-13. 
Townshend, J.R.G. \& Justice, C.O. (1986) Analysis of the dynamics of african vegetation using the normalized difference vegetation index. International Journal of Remote Sensing, 7, 14351445.

Vicente-Serrano, S.M., Delbart, N., Le Toan, T., \& Grippa, M. (2006) El Niño-Southern Oscillation influences on the interannual variability of leaf appearance dates in central Siberia. Geophysical Research Letters, 33, .

Vinogradov, B.V. (1977) Remote sensing in ecological botany. Remote Sensing of Environment, 6, 8394.

Vors, L.S. \& Boyce, M.S. (2009) Global declines of caribou and reindeer. Global change biology, 15, 2626-2633.

Walther, G.-R. (2010) Community and ecosystem responses to recent climate change. Philosophical Transactions of the Royal Society B: Biological Sciences, 365, 2019-2024.

Walther, G.-R., Post, E., Convey, P., Menzel, A., Parmesan, C., Beebee, T.J.C., Fromentin, J.-M., HoeghGuldberg, O., \& Bairlein, F. (2002) Ecological responses to recent climate change. Nature, 416, 389-395.

Walther, S., Voigt, M., Thum, T., Gonsamo, A., Zhang, Y., Köhler, P., Jung, M., Varlagin, A., \& Guanter, L. (2016) Satellite chlorophyll fluorescence measurements reveal large-scale decoupling of photosynthesis and greenness dynamics in boreal evergreen forests. Global change biology, 22, 2979-2996.

White, M.A., de Beurs, K.M., Didan, K., et al. (2009) Intercomparison, interpretation, and assessment of spring phenology in North America estimated from remote sensing for 1982-2006. Global Change Biology, 15, 2335-2359.

White, M.A., Hoffman, F., Hargrove, W.W., \& Nemani, R.R. (2005) A global framework for monitoring phenological responses to climate change. Geophysical Research Letters, 32, 1-4.

White, M.A. \& Nemani, R.R. (2003) Canopy duration has little influence on annual carbon storage in the deciduous broad leaf forest. Global Change Biology, 9, 967-972.

Woodward, F.I., Smith, T.M., \& Emanuel, W.R. (1995) A global land primary productivity and phytogeography model. Global Biogeochemical Cycles, 9, 471-490.

Zeng, B.C. (2013) Shifts in Arctic phenology in response to climate and anthropogenic factors as detected from multiple satellite time series. Environmental Research Letters, 8, .

Zhang, X., Friedl, M.A., Schaaf, C.B., Strahler, A.H., Hodges, J.C.F., Gao, F., Reed, B.C., \& Huete, A. (2003) Monitoring vegetation phenology using MODIS. Remote Sensing of Environment, 84, 471-475.

Zhou, G. (2016) Explaining inter-annual variability of gross primary productivity from plant phenology and physiology. Agricultural and Forest Meteorology, 226-227, 246-256. 
Nicolas Delbart is a professor in the geography department at Université de Paris, and is affiliated to the Paris Interdisciplinary Energy Research Institute. He was until recently involved at the PRODIG research unit, and previously at the Centre d'Etudes Spatiales de la Biosphère (CESBIO, (Toulouse, France), the Laboratoire des Sciences du Climat et de I'Environnement (LSCE, Gif-sur-Yvette, France) and at the Frontier Research Center for Global Change (FRCGC, Yokohama, Japan).

$\mathrm{He}$ is responsible for the master degree Remote Sensing and Geomatics Applied to Environmental Studies (in French, "Télédétection et Géomatique Appliquées à I'Environnement") and teaches remote sensing in the bachelor and master geography cursus.

His research focuses on the remote sensing of vegetation seasonal variations. In addition to his phenological studies in the northern ecosystems, his research addresses the phenology of crops in mixed pixels in France and the monitoring of forest density via the seasonal variations in the remote sensing signal, especially in Nepal. His research has also involved the use and validation of several dynamic vegetation models, and has extended to the remote sensing of water resources seasonal variations in semi-arid environments. 